\title{
Predicting the loss of ambulation in Duchenne muscular dystrophy
}

Prevendo a perda da marcha na distrofia muscular de Duchenne

Edmar Zanoteli

Departamento de Neurologia, Faculdade de Medicina, Universidade de São Paulo, Sao Paulo, SP, Brazil.

\section{Correspondence:}

Edmar Zanoteli

Departamento de Neurologia FMUSP

Av. Dr. Enéas de Carvalho Aguiar,

255 / sala 5131

05403-000 São Paulo SP - Brasil

E-mail address:zanoteli@terra.com.br

Conflict of interest:

There is no conflict of interest to declare.

Received 06 December 2013 Accepted 17 December 2013

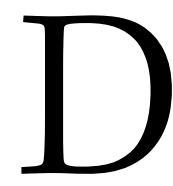
uchenne muscular dystrophy (DMD) is a devastating muscle disease with premature loss of ambulation ${ }^{1}$. The disease is caused by deficiency of the sarcolemmal protein dystrophin and results in weakness affecting the proximal portions of the limbs, usually starting during the third and fourth years of life, in association with progressive loss of functional abilities ${ }^{1}$. The unique medical treatment available is steroid therapy, which appears to prolong walking capacity by at least two years ${ }^{2,3}$. Strength loss, such as in hip extension and ankle dorsiflexion, is considered the primary predictor of loss of ambulation in $\mathrm{DMD}^{4}$, leading to progressively reduced walking capacity ${ }^{5,6}$. During the period of loss of ambulation, the children develop many compensatory movements to compensate for the weakness of limb-girdle muscles in the legs, such as the gluteus and quadriceps. The Gowers signal is the most famous compensatory movement, in which a patient,to rise from a sitting to a standing position, has to use his hands and arms to "walk" up his own body from a squatting position to compensate the reduced hip and thigh muscle strength. However, with the progression of the disease, compensatory movements are unable to avoid the loss of ambulation. Even in the first stage of the disease it is possible to quantify very early modifications in locomotion ${ }^{7}$. Doglio et al., using a Gait Analysis Laboratory, showed important functional changes in patients with DMD in the first stage of the disease ${ }^{7}$. These changes include alterations in spatial and temporal parameters (increases of cadence, and decreases of step length), increase in the range of anterior-posterior pelvic tilt and in pelvic rotation, in the pelvic obliquity and in the plantar-flexion of the ankle in swing. Differences in power generation and absorption at the hip joint and at the ankle joint were also detected, together with reduction in the flexor moment of the knee in mid-stance and in the dorsiflexor moment of the ankle in terminal stance with a consequent reduction in the peak-to-peak excursion.

Thus, besides medical treatment, the physical therapy in multidisciplinary care is imperative for alleviating muscle atrophy, skeletal deformities, and motor function deterioration $^{8}$. Physical therapy might improve the function of those muscles that are more affected in the lower limbs, especially in the period of loss of ambulation. In this way, qualitative analysis of compensatory movements during functional tasks in the critical periods of loss of ambulation may allow for recognition of important changes in synergies to help professionals provide more specific assistance and guidance to patients. Moreover, the use of steroids might prolong walking capacity while also modifying the compensation pattern. Consequently, analysis of the compensatory movements can also help during the follow up of steroid treatment response.

The paper presented in this volume by Martini et al. aimed to show the main compensatory movements in children with DMD immediately before walking loss. ${ }^{9}$ The authors described and quantified compensatory movements while sitting down/rising from the floor, and while climbing up/down steps. The most frequently observed compensatory movements were upper limbs support on the lower limbs/floor/handrail during all tasks and lumbar hyperlordosis, trunk support on handrail, equines foot, increased base of support, non-alternated descent, and pauses while climbing up/down steps. They also showed that sitting down/rising from the floor seems to be lost before climbing up/down steps in ambulatory children with DMD. 
The information provided by the analysis of the sequence of the functional loss and of the compensatory movements during the walking loss period is certainly helpful to follow up these patients, especially for physical therapy purposes and when they are taking steroids. Future evaluations, including those with a higher number of patients, prospective studies, and studies with similar physical therapy protocols, are necessary to confirm the results presented in that study. In addition, it is important to compare these results with measurements using traditional motor scales, such as the Motor Function Measure (MFM),the 6-minute walk test (6MWT), and the North Star Ambulatory Assessment (NSAA) ${ }^{3,5,6}$. Finally, patients' use of steroids could be tested to determine the variation of compensatory movements under the effects of medication.

\section{References}

1. Brooke MH, Fenichel GM, Griggs RC, Mendell JR, Moxley R, Florence J, et al. Duchenne muscular dystrophy: patterns of clinical progression and effects of supportive therapy. Neurology 1989;39:475-481.

2. Parreira SL, Resende MB, Zanoteli E, Carvalho MS, Marie SK, Reed UC. Comparison of motor strength and function in patients with Duchenne muscular dystrophy with or without steroid therapy. Arq Neuropsiquiatr 2010;68:683-688.

3. Silva EC, Machado DL, Resende MB, Silva RF, Zanoteli E, Reed UC. Motor function measure scale, steroid therapy and patients with Duchenne muscular dystrophy. Arq Neuropsiquiatr 2012;70:191-195.

4. Bakker JP, De Groot IJ, Beelen A, Lankhorst GJ. Predictive factors of cessation of ambulation in patients with Duchenne muscular dystrophy. Am J Phys Med Rehabil 2002; 81:906-912.

5. Mazzone E, Vasco G, Sormani MP, et al. Functional changes in Duchenne muscular dystrophy: a 12-month longitudinal cohort study. Neurology 2011;77:250-256.
6. Bérard C, Payan C, Hodgkinson I, Fermanian J; MFM Collaborative Study Group. A motor function measure for neuromuscular diseases. Construction and validation study. Neuromuscul Disord 2005;15:463-470.

7. Doglio L, Pavan E, Pernigotti I, Petralia P, Frigo C, Minetti C. Early signs of gait deviation in Duchenne muscular dystrophy. Eur J Phys Rehabil Med 2011;47:587-594

8. Bushby K, Finkel R, Birnkrant DJ, et al. DMD Care Considerations Working Group. Diagnosis and management of Duchenne muscular dystrophy, part 2: implementation of multidisciplinary care. Lancet Neurol 2010;9:177-189.

9. Martini J, Voos MC, Hukuda ME, Resende MBD, Caromano FA. Compensatory movements during functional activities in ambulatory children with Duchenne muscular dystrophy. Arq Neuropsiquiatr 2014;72:5-11. 